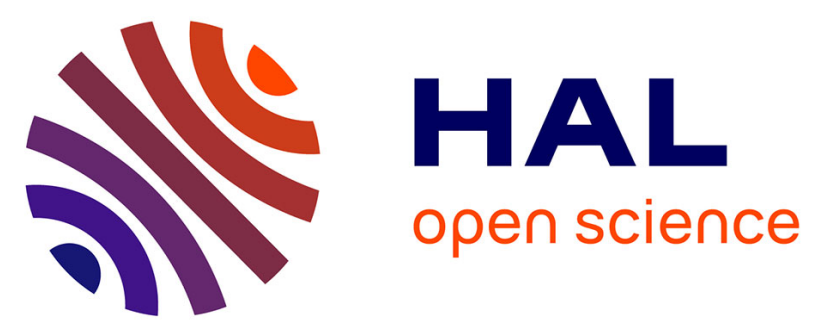

\title{
On the Epistemic and Social Foundations of Mathematics as Tool and Instrument in Observatories, 1793-1846
}

David Aubin

\section{- To cite this version:}

David Aubin. On the Epistemic and Social Foundations of Mathematics as Tool and Instrument in Observatories, 1793-1846. Johannes Lenhard \& Martin Carrier,. Mathematics as a Tool: Tracing New Roles of Mathematics in the Sciences, 327, Springer, p. 177-196, 2017, Boston Studies in the Philosophy and History of Science. hal-01269674

\section{HAL Id: hal-01269674 https://hal.sorbonne-universite.fr/hal-01269674}

Submitted on 5 Feb 2016

HAL is a multi-disciplinary open access archive for the deposit and dissemination of scientific research documents, whether they are published or not. The documents may come from teaching and research institutions in France or abroad, or from public or private research centers.
L'archive ouverte pluridisciplinaire HAL, est destinée au dépôt et à la diffusion de documents scientifiques de niveau recherche, publiés ou non, émanant des établissements d'enseignement et de recherche français ou étrangers, des laboratoires publics ou privés. 


\title{
On the Epistemic and Social Foundations of Mathematics as Tool and Instrument in Observatories, 1793-1846
}

\author{
David Aubin* \\ May 2015, revised February 2016
}

The astronomer is dependent on his tools; the observatory is but the receptacle of his tools, his tool-chest so to speak (Harrington 1883-1884, 249).

One night, in June 1782, the Astronomer Royal Nevil Maskelyne suddenly felt "much out of love with his instrument." William Herschel had come to Greenwich to stargaze in his company and Maskelyne had welcomed him. But to realize that all telescopes in the Royal Observatory were so much inferior to Herschel's new reflector was disheartening to the Astronomer Royal. Observatory scientists indeed loved their instruments. In their publications, they devoted hundreds of pages to the description of telescopes. They drew them in exquisite details. They lobbied for years to obtain the requisite funds to buy the most precise instruments, only to wait even longer for the most reputable makers finally to provide them. Then, they spent hours and hours chasing and charting their inevitable defects. They discussed at great lengths the operations required for their perfect calibration, attended to their proper care, and improved them constantly (see, e.g., Carl 1863, Bell 1922, King 1955, Chapman 1996). Much more rarely, however, did tools command their attention.

Astronomers, as we know, also loved mathematics. "Every part of the operations of an observatory is mathematical," wrote one of Maskelyne's successors, George Biddell Airy (1801-1892), in a memo dated December 4, 1861. ${ }^{2}$ In the practice of observatory scientists, mathematical theories and methods often were as central as their instruments. As the

\footnotetext{
*Sorbonne Universités, UPMC Univ paris 6, UMR 7586, Institut de mathématiques de Jussieu-Paris Rive Gauche, CNRS, Univ Paris Diderot, Sorbonne Paris Cité, F-75252 Paris, FRANCE.david.aubin@upmc.fr.

${ }^{1}$ William to Caroline Herschel, June 5, 1782; in Lubbock (1933), 115.

2 "Remarks on the neglect, by the Junior Assistants, of the course of education and scientific preparation recommended to them," Airy Papers, Cambridge University Library, RGO 6/43, 235. About this memo, see (Aubin 2009, 273 and 276-277).
} 
Königsberg Observatory director Friedrich Wilhelm Bessel (1784-1846) famously commented, mathematical corrections themselves improved the precision of telescopes:

Every instrument is made twice, once in the workshop of the artisan, in brass and steel, but then again by the astronomer on paper, by means of the list of necessary corrections, which he determines in his investigations. ${ }^{3}$

In view of examining how scientists used mathematics as a tool, we therefore see that the specific cultural and epistemological spaces delineated by astronomical observatories provide a promising terrain for a careful study of attitudes with respect to mathematics, tools, and instruments, and to their interactions.

Observatory scientists themselves compared mathematics to their most cherished instruments. Logarithms, for example, were seen as an "admirable artifice that, by shortening computations, extends astronomers' lives [just as] the telescope ha[s] increased their sight" (Biot 1803, 26). The link between the telescope and the logarithm echoed Kepler's striking frontispiece to the Rudolphine Tables (1627) where "in the upper part, inventions that were the most useful to Astronomy are represented: Galileo's telescope, Napier's logarithms, and Kepler's ellipse" (Delambre 1821, 1:558; see figure 1). In astronomical context, the comparison between a mathematical device, the logarithm, and a physical instrument, the telescope, was explicit.

Of course, one has to remember that the word "instrument" is ambiguous (Van Helden \& Henkins 1994). In the Novum Organum, Francis Bacon described the way in which "Man, Nature[']s Minister and Interpreter," was able to act and understand through experience and reason. In its original seventeenth-century English translation, Bacon's second aphorism read: Things are performed by instruments and helps, which the Understanding needs as much as the Hand. Now as Mechanick Instruments assist and govern the Hands motion, likewise the instruments of the Understanding prompt and advise it (Bacon 1676, 1; quoted in Taub 2011, 691).

In this sense, it is self-evident that telescopes, logarithms, and ellipses should be thought of as different types of instruments for the eye or for the mind. ${ }^{4}$ But, going beyond this simple

3 Bessel (1848), 432; quoted in Hammel (1984, 40); trans. Crowe (1994), 156: “Jedes Instrument wird auf diese Art zweimal gemacht, einmal in der Werkstatt des Künstlers von Messing und Stahl; zum zweitenmale aber von dem Astronomen aud seinem Papiere, durch die Register der nöthingen Verbesserungen, welche er durch seine Untersuchung erlangt.” 
identification, how can we situate more precisely the astronomer's mathematical practices with respect to their instrumental practices? In earlier publications, we have offered a synthetic discussion of "observatory techniques" over the long nineteenth century (Aubin, Bigg, and Sibum 2010, Aubin 2015). Characteristic of the observatory culture, such techniques involved instrumental technology and observation practices, the social organization of working practices, and cognitive tools such as mathematical theories and methods. Whether they originated or not in this culture, observatory techniques formed a coherent set of practices and technologies. A specific aspect of the observatory culture was the role played by numbers and their collection, manipulation, storage, and transformation. Mathematics, I argued elsewhere, was just another instrument in observatory scientists' panoply (Aubin 2009, 282).

The present chapter is intended as a contribution to the philosophical debate regarding the "unreasonable effectiveness," or applicability of mathematics to the natural sciences (Wigner 1960, Steiner 1998, Bangu 2012). If we take seriously the idea that mathematics was conceived as a tool or as an instrument — and, as I try to show, I believe that we must - then we need to pay attention to a few things. First, as Steiner has argued, this conception of the applicability of mathematics will slide the problem away from concepts, laws, and language to practice. ${ }^{5}$ On what ground indeed could a telescope be applied to the understanding of astronomical phenomena? This had very little to do with the way the instrument expressed scientific truths, but everything to do with the way it was devised, built, maintained, studied, and used. Second, to make the comparison with mathematics effective and culturally meaningful, I believe it is essential to pay a closer attention to the variety of material tools and

\footnotetext{
${ }^{4}$ In this article, I shall not refer to the "mathematical instruments" tradition, which obviously played a role in shaping the conception of instruments in the observatory culture. By the late 18th century, astronomers were relying on highly skilled makers, such as Jesse Ramsey and Edward Troughton, fellows of the Royal Society whose names were, as we shall see, routinely attached to the high-precision instruments they produced (Bennett 2011; see also Chapman 1995).

${ }^{5}$ As expressed by Gottlob Frege in 1884, there is a simple solution to the applicability problem: "The laws of numbers, therefore, are not really applicable to external things; they are not laws of nature. They are, however, applicable to judgments holding good of things in the external world: they are laws of the laws of nature" (Frege 1980, quoted by Wilholt 2006, 74). For another visions of mathematics as a language in this context, see Sarukkai (2005).
} 
instruments one encounters in relevant scientific environments. Documenting the case of the Paris Observatory in 1793, I am led to distinguish, for the sake of my argument, between scientific instruments and mere tools, and among the latter between simple tools and highprecision tools. Third, as I show, such distinctions necessarily involved social criteria regarding users and the conditions of their use of devices. There were therefore high stakes in terms of users' status in designating their equipment as tools or instruments. Fourth, these distinctions also applied to the way mathematics was used by various people as tool and as instrument. Like in the philosophy of mathematical practice (Mancosu 2008), this approach shifts the focus of our attention from mathematical foundations to a wider range of practices. Looking at the computers' daily routine at Greenwich in 1839, I exemplify the various meanings mathematics as a tool can have there.

Finally, pursuing this approach raises the questions: How far can the analogy between mathematics and tools or instruments go? Have the notions of care, improvements, maintenance, and fixes corresponding meanings as far as mathematical instruments are concerned? Did astronomers develop with regards to their mathematical instruments the same kind of personal attachment, intimate knowledge about the ins and outs, and attention to the life history of their most prized material instruments? To provide extensive answers to such interrogation would be enough for a whole research program. With the perspective I adopt here, there are a number of cases in the history of mathematics that might be revisited with profit. Astronomers tinkered over and over again with the mathematical instruments that were handed down to them in order to increase their precision. ${ }^{6}$ In the last part of this paper, I will illustrate the fruitfulness of this approach by considering the case of Bessel functions.

\section{Tools vs. Instruments in the Paris Observatory, 1793}

To try and make sense of the distinction between tools and instruments in the context of the observatory, one may look at inventories. Take the case of the "inventory of instruments of the National Observatory in Paris" from 1793. ${ }^{7}$ This report was drafted in rather dramatic

\footnotetext{
${ }^{6}$ One may think, among other cases, of the Gauss-Laplace theory of errors (Sheynin 1973) or Poincaré's qualitative dynamics (Roque 2015).

${ }^{7}$ See "Pièce justificative $\mathrm{N}^{\circ} \mathrm{X}$ : Inventaire des instrumens de l'Observatoire national de Paris en 1793," Archives nationales F17/1219; Archives de l'Observatoire D.5.38; repr. (Cassini 1810, 208-217). The date of this report is uncertain, but September 19, 1793 is a reasonable estimate (Wolf 1902, 349). Dated "19 of the first month of Year II" [which should be 19
} 
circumstances. Following the abolition of the Academy of Sciences by the Republican Government, the traditional organization of the Paris Observatory under the Cassini dynasty was overturned. A decree stated that the Observatory was to be "republicanized" and that the former director Jean-Dominique Cassini, also known as Cassini IV, would loose all prerogatives over his former assistants. As a result Cassini resigned from his position and, on September 19, 1793, a delegation was sent to the Paris Observatory in order to draw a list of all its instruments.

With respect to the distinction between instruments and tools [outils], this inventory is highly revealing, in part because it was written, not by astronomers, but by the delegates appointed by the Revolutionary Commission temporaire des arts, set up by Government following the suppression of the Academy of Science in August $1793{ }^{8}$ These delegates were the physicist Jacques Charles (1746-1823), and the instrument makers Étienne Lenoir (17441832 ) and Jean Fortin (1750-1831) who unlike scientists were not highly experienced as writers. Fully conscious of what was at stake, Cassini however oversaw the inventory with keen eyes, as well as Jean Perny de Villeneuve (1765-?), Cassini's former assistant and now temporary director of the Observatory, and the young Alexis Bouvard (1767-1843), who would stay at the observatory for the next fifty years. ${ }^{9}$

The inventory of instruments drafted by the commissioners was divided in several sections: clocks (17 items), refracting telescopes (13), achromatic objectives (4), simple objectives (26), reflectors (5), micrometers (13), generic instruments (26), andinterestingly_- "tools and bits of machines" [outils et débris de machines] (24). As we can see, "tools" were listed here as special kinds of "instruments," but perhaps not as highly valued as

vendémaire, that is, October 10], the report was said to be completed when discussed by the Commission temporaire des arts on September 26. According to his biographer, Cassini left the Observatory never to come back, on October 3rd (S.-Devic 1851, 205).

${ }^{8}$ Informations about the Commission and these commissioners in particular can be found in its proceedings (Tuetet 1912). On scientific instruments at this time, see also Daumas (1953). On Charles, see (Blondel 2003).

${ }^{9}$ Under the Terror, Cassini was jailed in the English Benedictine Convent on February 14, 1794. He was freed after Robespierre's downfall, on August 5, 1794, but never returned to the Observatory. For more information on the history of the Paris Observatory during the French Revolution, I refer to Chapin (1990) and Aubin (2013); more complete accounts in French can be found in Cassini (1810), S.-Devic (1851), and Wolf (1902). 
the others, as can be inferred from their showing up pell-mell with other bits and pieces at the end of the inventory. ${ }^{10}$ Astronomers' knowledge about their instruments was rather intimate: their dimensions, origins, flaws, and present states were all precisely established. The most valuable ones had proper names attached to them and in fact often were the combination of several instruments. The first refracting telescope was described as such:

$\mathrm{N}^{\circ}$ 1. Achromatic telescope by Dollond, objective with three glass [pieces] of 42 lines of aperture, 3 feet and half of focal length; it has three oculars, one terrestrial and two celestial ones; it is mounted on a mahogany stand with cupper columns with all its motions; to this telescope an heliometer by Bouger can be fitted, simple objective, plus a wire micrometer by Hautpois. ${ }^{11}$

Let us emphasize the individuality of such instruments. Cassini for example remembered having used Dollond's refractor to observe the phases of Saturn in 1774 (Cassini 1793, 153). Also known as the lunette du prince de Conti because the Prince had bought it after the Duke of Chaulnes's death in 1769, the Dollond refractor was rented to Cassini III on several occasions and sold to the Observatory in 1778 (Wolf 1902, 242-243; Barty-King 1986, 92). Found to have serious defects, it was neglected at the time of the inventory.

"Tools" in contrast were more generic, even when they were better built. In fact, the tools mentioned in the inventory were not simple tools like hammers or screwdrivers, but rather high-precision special-purpose tools, like three long steel rulers, which had been "worked for an infinite [amount of] time and with infinite care to obtain a straight line," and drawing marble tables "polished in mirror-like manner" (Cassini 1810, 215-216). These tools, Cassini explained in a footnote added later, had been acquired to equip the workshop set up in 1784 at the Observatory in an ill-fated attempt at fostering the development of high-precision instrument making in Paris (Wolf 1902, 277-286; Daumas 1953, 358-360). Only the most notable tools therefore were deemed worthy of mention in the inventory, as they already were in Cassini's detailed account books, which specified the price that had been paid for the steel rulers and the marble tables (respectively, 480 and 368 livres [Wolf 1902, 279-280]).

\footnotetext{
${ }^{10}$ About instruments in state of disrepair, see Schaffer (2011).

${ }^{11}$ Cassini 1810, 209: "No 1 . Lunette achromatique de Dollond, objectif à trois verres de 42 lignes d'ouverture, 3 pieds et demi de foyer; elle a trois oculaires, un terrestre et deux célestes; elle est montée sur un pied d'acajou à colonne de cuivre avec tous ses mouvemens; à cette lunette s'adapte un héliomètre de Bouger, objectif simple, plus un micromètre filaire de Hautpois."
} 
Although much higher, the cost of furnishing and equipping the workshop with common tools were significantly given in bulk in Cassini's accounts.

While there was no entry for the word instrument in Diderot and D'Alembert's Encyclopédie a generic definition was given to outil by Louis de Jaucourt, one of the most prolific contributors to the encyclopedia. He provided a similar distinction between tools and instruments:

ToOL, (...) an instrument used by workmen and artisans to work on the different tasks of their professions, crafts, and trades; thus are hammers, compasses, planes, squares, braces, etc. [...] Let us simply add that workmen distinguish somewhat between tools and instruments, and that not all instruments are tools. ${ }^{12}$

Jaucourt's definition echoed the inventory made by Charles, Fortin, and Lenoir who agreed that tools were a specific genre of instruments, albeit less noble, not all instruments being tools. In a book by Louis Cotte (1740-1815), one finds more complex and more interesting webs of meaning around those terms. ${ }^{13}$ Intent of showing in his Vocabulaire portatif des mécaniques that the beauty of God's work was no less present in the products of human art and industry than in Nature, Cotte explained the differences among the terms machine, instrument, apparatus, and tool:

We understand by machine a combination of several simple machines, such as the lever, the winch, the pulley, etc. whose action is to stand in for man's strength and to produce great effects in little time and at little expanse in all mechanical operations in which they are employed. [...] The instrument is a kind of machine, but [one] susceptible of great precision, to be employed in scientific operations which require accuracy, like astronomy, practical geometry, surgery, etc. The apparatus is a combination of different instruments whose combination contributes to the demonstration of physical, mathematical, and chemical truths. The tool is a simple

\footnotetext{
${ }^{12}$ Diderot and D'Alembert, 11: 718, original emphasis: “OuTIL, (...) instrument dont les ouvriers \& artisans se servent pour travailler aux différens ouvrages de leur profession, art \& métier; tels sont les marteaux, les compas, les rabots, les équerres, les villebrequins, $\& c$. [...] Nous ajoutons seulement que les ouvriers mettent quelque différence entre les outils \& les instrumens; tout outil étant instrument, \& tout instrument n'étant point outil." ${ }^{13}$ Father Cotte, a cleric, is known for his work on meteorology and on the popularization of natural history, physics, and astronomy. See Pueyo (1994).
} 
instrument, often of the sort of the wedge, which is useful in the manual and common operations of the crafts and trades. ${ }^{14}$

In Cotte's view, tools were simple instruments, which themselves were a special sort of machines. The distinctions he established were based on two criteria: dichotomy between simplicity and precision, on the one hand, and the kinds of operations they were employed in, on the other. Instruments were characterized by precision and their use in operations geared at discovering new truths about nature, whereas tools were necessary simple and to be used by craftsmen in their daily and mundane occupations. ${ }^{15}$

Going back to the Paris Observatory inventory, we see that Cotte's criteria apply well, but not completely. In the inventory, the only explicit distinction was social. "Instruments" were high-precision objects used by savants in their scientific operations in order to uncover scientific truths, whereas "tools" were to be used by craftsmen and makers in the workshop. But there was nothing common or mundane about the tools listed, and their precision seemed highly valued. At the Paris Observatory, tools were specialized instruments acquired to help artisans make the optical instruments required by astronomers. Instruments surely lay both

${ }^{14}$ Cotte 1801, viii-ix, original emphasis: "On entend par Machine une combinaison de plusieurs machines simples, telles que le levier, le treuil, la poulie, etc. dont le résultat est de suppléer aux forces de l'homme et de produire de grands effets en peu de tems et avec peu de dépense dans toutes les Opérations mécaniques où elles sont employees [...]. L'Instrument est bien aussi une espèce de machine, mais susceptible d'un très-grande precision, pour pouvoir être employee dans les Opérations scientifiques qui demandent de l'exactitude, comme l'astronomie, la géométrie pratique, la chirurgie, etc. L'Appareil est une combinaison de différens instrumens dont la reunion concourt à démontrer les vérités physiques, mathématiques, chimiques, etc. L'Outil est un instrument simple, le plus souvent de l'espèce du coin, qui sert dans les Opérations manuelles et habituelles des arts et des métiers." ${ }^{15}$ It is interesting to note that, in the definition of the word instrument, the Oxford English Dictionary today explains, similarly, that the distinction between tools, instruments, and machines, is based on social, rather than lexicographical, grounds: "Now usually distinguished from a tool, as being used for more delicate work or for artistic or scientific purposes; a workman or artisan has his tools, a draughtsman, surgeon, dentist, astronomical observer, his instruments. Distinguished from a machine, as being simpler, having less mechanism, and doing less work of itself; but the terms overlap." Note added to the definition of "Instrument" (www.oed.com). 
literally and figuratively at the center of the observatory, but the place of tools was ambiguous in this cultural space. While simple tools went unmentioned, some of the high-precision tools found their place in the list side by side with instruments. Like instruments, such tools possessed their own history and individuality, but they were to be used by different people.

There is a final twist we need to take into account. In a culture that praised inventiveness, to design one's own tools might however be good ground for claiming some degree of recognition from the astronomers' part. At the end of the seventeenth century, Abraham Sharp, John Flamsteed's assistant at Greenwich, thus was highly praised for his skill as an observer and as a mathematician, but also for talent as a mechanic, having "made himself most of the tools used by joiners, clock-makers, opticians, mathematical-instrument-makers, \&c." (Anonymous 1781, 462). When the Dudley Observatory was built in Albany, New York, in 1856, the overseeing board duly noted the director Benjamin Apthorp Gould's technical ingenuity with his tools:

Great difficulties were encountered in boring or drilling the horizontal holes through the stone piers of the meridian circle, a difficulty attributed by Dr. Gould in great measure to the inefficiency of the tools. He changed the whole character of the drills, using cast iron instead of steel; and with much simpler appliances has accomplished the work successfully (Henry, Bache, and Pierce 1858, 23). ${ }^{16}$

The use of tools was reserved to people with a lower status in the observatory, but inventively tinkering with them could help assistants and astronomers alike gain recognition.

\section{The Eight-Hour Day: Mathematics as a Tool at Greenwich, 1839}

In this context, whether observatory mathematics could be seen as a simple tool, a highprecision tool, or an instrument crucially hinged on the way it was put to use: Who would use it? How? And to what purpose? To examine this issue, let us focus on the Royal Observatory Greenwich under Airy's directorship. In the memo quoted above, Airy explicitly spelt out his view of the place of mathematics in an observatory.

The action and faults of telescopes and microscopes require for their understanding a knowledge of Mathematical Optics. Every discussion and interpretation of the observations requires Mathematical Astronomy. The higher problems, such as the

\footnotetext{
${ }^{16}$ On the history of this observatory, see Wise (2004).
} 
discovery of the elements of a comet's orbit from observations, require the high Mathematics of Gravitational Astronomy. ${ }^{17}$

In short, mathematics was everywhere. Moreover, in Airy's understanding, formal hierarchies among personnel hinged on their level of mathematical knowledge much more than anything else. ${ }^{18}$ At the bottom of the scale, were supernumerary computers. In addition to being able to "write a good hand and good figures" and "to write well from dictation, to spell correctly and to punctuate fairly", computers were to have rudimentary mathematical knowledge, essentially restricted to arithmetic, including vulgar and decimal fractions, extraction of square roots, use of logarithms, and the use of \pm . Next came the Assistant, first, second and third grades, whose competencies were mostly evaluated through their knowledge of mathematics, from simple Euclidean geometry to analytical mechanics "especially in reference to Gravitational Astronomy."

In Airy's observatory, computers were the mathematical artisans of the observatory, and, as such, I would like to say that they used mathematics as a tool, and not as an instrument. They used mathematics like apprentices in optical workshops handled the basic unspoken tools such as drills and bores, and not like astronomers manipulated telescopes in observatories. To illustrate this point, let us focus on a significant episode of the labor history of computing: the way in which Greenwich computers earned the eight-hour day. ${ }^{19}$

It all started on Monday afternoon, January 21, 1839. Computers were chitchatting in the Royal Observatory's Octagon Room. Rain had fallen nearly all day and the Astronomer Royal had left for London. ${ }^{20}$ One of them started to complain about their working conditions. His was a new face in the room: some H. W. Bowman who had just been hired. His age is unknown, but like most of the other computers there, he must have been very young, twenty years old at the most. Less than two weeks earlier, Airy had described what Bowman's new job would be about: "The work is almost entirely of calculation, and it is highly important that

17 "Remarks on the neglect, by the Junior Assistants, of the course of education and scientific preparation recommended to them" (Dec. 4, 1861). RGO 6/43, 235.

${ }^{18}$ Several slightly different copies of this memo are extent in Airy's papers in Cambridge University Library. A first draft was written on November 20, 1856 and a slightly revised version was adopted on May 10, 1857. In the following I quote from RGO 6/43, 170-175. For a more detailed analysis of this memo, see (Aubin 2009, 277).

${ }^{19}$ For a study of the division of computing labor at Greenwich, see Grier (2005).

${ }^{20}$ RGO 6/24/33: Airy's Diary. 
the computer should understand the use of the + and - signs in the various operations of additions, subtraction, multiplication and division. ${ }^{, 21}$ Before a formal offer could be made to Bowman, it was agreed that the head of the computing bureau, J. W. Thomas, would check the value of his work. Now, Bowman seemed unhappy with the job. If he were to work so many hours, he lamented to his colleagues, he could not possibly live long. Typically, computers at Greenwich worked from 8 a.m. to 8 p.m.; they had a one-hour break for dinner, while Saturday afternoons and Sundays were free. Therefore, Bowman went on, "time must have some weight in making [him] an offer."22

Brought in the observatory as a computer, Bowman seems to have had few skills worth bragging about. At first he had trouble with additions and subtractions: "He knew nothing of either," his superior Thomas reported. "The - he called a stroke and the + he called a cross and he considered the sign $\times$ equally the same." Asked to find the logarithm of the sine of $42^{\circ} 19^{\prime}$ in Jean-François Callet's Tables portatives (published in 1783 on the basis of William Gardiner's), Bowman did not know where to begin. But despite foreboding beginnings, two weeks later Thomas was forced to aver that Bowman "has come pretty middling - he can add $-x$ and $\div$ very well providing the numbers be of one denomination." All in all, depending on whether he was willing to study or not, the new recruit could "be valued equal Mr Richard Dunkin.",23

This comparison spoke highly in favor of Bowman. Richard Dunkin was the son of William Dunkin, himself a computer of considerable experience who had worked for the Nautical Almanac for more than twenty years. Hired at twenty-three, he was allowed to stay in Truro, Cornwall, working in his home. In 1832 when the Nautical Almanac Office was established in London by its new superintendent Lieutenant William Samuel Stratford, to his regret Dunkin Sr. was forced to leave with his family his "semi-independent position at

\footnotetext{
${ }^{21}$ Airy to Bowman (January 8, 1839). RGO 6/526, 86.

${ }^{22}$ Thomas to Airy (21 January 1839). RGO 6/525, 29, orig. emphasis; Dunkin (1999), 72.

${ }^{23}$ All quotations in the above paragraph from Thomas to Airy (21 January 1839). RGO 6/524 File 10bis, 352, orig. emphasis. "Units of the same kind but of different magnitudes, as pounds, shillings, pence, and farthings, which are units of value (...) are called units of different denominations" (De Morgan 1831, 25).
} 
Truro," and accept a "daily sedentary confinement to an office-desk for a stated number of hours in the company of colleagues all junior to himself in age and habits." 24

William Dunkin never ceased to regret his previous life. Like many in his cohort who reluctantly saw the industrial age forced upon them, Dunkin wished his sons to do better. Having worked as a miner in his youth, he remembered that: "the underground tributer's work was occasionally far more lucrative than the scientific work to which his after-life was devoted" (Dunkin 1999, 42-43). He thus took great care of his sons' education which he expected would help them get a foothold in business: "His great desire was that they should be educated for a mercantile life, and that they should not become computers. As a computer all his life from youth, he always, and perhaps truly, considered that it was not a profession that gave much prospect of advancement in social position" (Dunkin 1999, 46). In Camden Town, where the Dunkins had their house, the boys were schooled at Wellington House (where Charles Dickens had been a pupil in 1824-27). Later, at least two of them were sent a French boarding school, near Calais.

But sorrows repeatedly stroke the Dunkins. William's first son died in March 1832. Three years later, an abscess formed on one of his feet and would not go away. The walk to the Nautical Almanac Office got harder and harder until William was allowed to compute at home again. Meanwhile, in less than five weeks in the spring of 1836 two more of Dunkin's children, a boy and a girl, had died. On July 3, 1838, William Dunkin also passed away, leaving his wife alone with two boys: Richard aged 15 and Edwin two years his elder. Lieutenant Stratford knew the Dunkin family was in duress when he recommended the boys to Airy. Richard and Edwin were recalled from their boarding school in Calais (Dunkin 1896, 197), and in August of that year, both joined Airy's team of computers, where the boys quickly proved to be excellent.

On January 21, 1839, after having reported Bowman's complaints to his boss, Thomas nonetheless warned Airy that if working conditions remained too harsh, the Dunkins might lend receptive ears to offers they might receive from elsewhere- "and to lose these two would be a great loss." 25 Bowman indeed was not alone to whine about the practical aspects

\footnotetext{
${ }^{24}$ Dunkin (1999), 45. Stratford (1791-1853) entered the Navy on 10 February 1806; he was the first secretary of the Royal Astronomical Society in 1826-31 and superintendent of the Nautical Almanac from 1830 to his death. On the story of this institution up to that point, see Dunkin (1898) and Croarken (2003).

${ }^{25}$ All quotes are from Thomas to Airy (January 21, 1839). RGO 6/525, 29.
} 
of his new job. Earlier, a young computer named Thaddeus Foley also had had his conflict with Thomas: he "condemns the place. He styles it a beastly place, a slavery, and that no one but a half starved beggar would stop in it." ${ }^{, 26}$ Consulted on the matter, Lieutenant Stratford could not hide his surprise at Airy's readiness to "binding persons" for so long every day. ${ }^{27}$ How could the Astronomer Royal expect work to be done well in such conditions? "As to myself," Thomas the overseer went on, "I complain not," but like Stratford he supported his computers' complaints, if only for fear of injuring the work.

Being constant at work a person becomes stupefied and although still working at the same rate now begins to commit blunders and the examiner will with the same state of mind run over them and mark them as correct—-such has been the case and such will be the case. And I am confident that to continue to work 11 hours a day much longer will not answer the purpose. ${ }^{28}$

In the culture of the nineteenth observatory, precision was everything (Wise 1995). The paradox of the computer's work therefore was posed as such: how could one rest assured that a low-skilled employee with a small pay would be carrying out a tedious and repetitive task for several long hours every day without making any error; and when errors inevitably occurred, how could they be promptly detected? In the event, the Astronomer Royal was sensitive to Thomas's argument. He agreed to reduce working hours from 8 a.m. to 5 p.m. with an hour break, or from 8 p.m. to 4 p.m. if the computers were to take no break at all. Everyone agreed they preferred to finish at the earliest time possible. The Greenwich computers had earned the eight-hour day.

Social progress notwithstanding, this episode-perhaps more than the case of the personal equation to which we shall come back-illustrates the way in which Airy's observatory was transformed into a factory with a strict discipline (Schaffer 1988). The mathematics mobilized by computers consisted of simple tools indeed and their work was mostly manual. Mathematics was for sure used as a tool at Greenwich: it was a tool, and perhaps a machine-tool, used by computers to perform a task assigned to them under the

\footnotetext{
${ }^{26}$ Thomas to Airy (undated [1838]). RGO 6/525, 15, orig. emphasis. Esq. Mathematical Master at the Royal Naval School, Camberwell, Foley was later elected a Fellow of the Royal Astronomical Society; see Monthly Notices of the Royal Astronomical Society 6 (1844), 52. ${ }^{27}$ Stratford's opinions about computers are in Thomas to Airy (21 January 1839). RGO 6/525 File 1, 29.

${ }^{28}$ Thomas to Airy (January 21, 1839). RGO 6/525 File 1, 29.
} 
constant supervision of their boss, it was a tool used by assistant to climb up the hierarchy, it was a tool used by the observatory director to assert his authority over his staff and the general public. But, as a simple tool, it hardly deserved special attention. These aspects of the use of mathematics in the observatory leaving few public records are therefore rather hard to study historically. There are however instances when mathematics ceased to be a simple tool and became one of the most powerful instruments at observatory scientists' disposal.

\section{Improving Instruments with Mathematics and Mathematics as an Instrument in}

\section{Königsberg, 1815-1824}

In the observatory context, using mathematics as an instrument is a whole other matter than using as a simple tool. Like all other instruments — or, rather, in combination with themmathematics used as an instrument was put to the service of increasing precision. At the end of his life, Bessel was already terminally ill when on October 5, 1854 he wrote a touching letter to Airy. ${ }^{29}$ Referring to the publication over which Airy's computers had toiled for years, Bessel expressed his great pleasure "in the evening of my scientific life to see a work completed on whose advancement I have bestowed a great part of the morning and noon of that life." ${ }^{30}$ He praised the Astronomer Royal for having "brought through to an end the great and still extending labour" and recalled how at the beginning of his career he had set on the similar task that would be Airy's main inspiration:

When, forty years ago, I entered upon my astronomical course, and found myself in the full possession of the bodily strength and activity which are indispensable to render a life useful to science, I found myself naturally obliged to consider carefully the state of astronomy, and to exert myself to make out clearly what must be done in order to establish it more firmly than it appeared to be established: in order to give it a form which should not withdraw itself from the ever-advancing improvement (founded on the very nature of science) in our knowledge of the heavenly movements, but should rather enable us to increase progressively the correctness of the earlier determination by the use of the later observations, so that they might asymptotically draw near to the truth which never can be reached (ibid.).

\footnotetext{
${ }^{29}$ On Bessel, see Hammel (1984) and Ławrynowicz (1995), as well as Olesko (1991). ${ }^{30}$ Bessel to Airy (October 5, 1845). RGO 6/530, 75-76. I quote from one of the two (nearly identical) English translations in Airy’s papers (ibid., 76-78 and 79-80).
} 
To improve the correctness of observations made earlier led Bessel to study carefully every source of errors he could think of. Errors of astronomical observation, he wrote, formed two classes: those that "are dependent on innumerable accidental causes and therefore can be considered to follow the general propositions of the calculus of probability" and those "that are provoked by constantly acting causes and which are to be ascribed to the deviation of the instruments from their mathematical ideal or from their manner of treatment." 31 Skirting around the issue of the personal equation, Bessel had first believed that the second class of errors could be diminished "through the insight of the observer and rigour in the investigation of the instrument and in the method of observation" (ibid., orig. emphasis). By carefully tracking down Bessel's role in the well-visited history of the personal equation, Christoph Hoffmann (2007) has reminded us that in this case the observer was not considered as a human laborer in need of discipline, but rather as a source of errors among others. ${ }^{32}$

For our purpose, Bessel's final treatment of the personal equation rather points toward the conclusion that mathematics served in the hand of the skilled astronomer as a highprecision tool that would improve the accuracy of observation, whether by investigating the instrument, the physical conditions in which it was used, or even physiological differences between observers. Bessel's Tabulae Regiomontanae (in 1830) were a masterwork of error analysis based on Greenwich observations of fundamental stars (including Maskelyne's) and gave the mean and apparent motions of 38 stars from 1750 to 1850. About these tables, John Herschel (son of William's) wrote: "It affords the first example of the complete and thorough reduction of great series of observations, grounded, in the first instance, on a rigorous investigation, from the observations themselves, of all the instrumental errors, and carried out on a uniform plan, neglecting no minutiæ which a refined analysis and a perfect system of computation could afford" (Herschel 1847, 203-204). Herschel also quoted the Danish astronomer Heinrich Christian Schumacher (1780-1850) according to whom: "One may almost assert that one exact and able calculator is capable of doing better service to

\footnotetext{
${ }^{31}$ Bessel (1820), 19; trans. Hoffmann (2007), 346, my emphasis: "die eine enthält die eigentlichen Beobachtungsfehler, die von unzähligen zufälligen Ursachen abhängen und deshalb den allgemeinen Sätzen der Wahrscheinlichkeitsrechnung folgend angesehen werden können; die andere begreift die von beständig einwirkenden Ursachen herrührenden, der Abweichung der Instrumente von ihrer mathematischen Idee, oder ihrer Behandlungsart zuzuschreibenden."

${ }^{32}$ On the personal equation, see also Schaffer (1988) and Canales (2001).
} 
astronomical science than two new observatories" (ibid., 203). In this sense, mathematics truly replaced optical instruments.

In Bessel's practice, mathematics was thoroughly used as a specialized tool, like the expensive rulers and marble tables found at the Paris Observatory, and his innovative use of such tool drew attention to his work. In a letter to Airy about his method (November 9, 1833), Bessel commented that: "[i]t would be useless, to enter here into the particularities of the computations" (Bessel 1875-1876, 3:462). There was no need to discuss such simple tools as mere computation. To improve the precision of the observations by means of the mathematical treatment of raw data, Bessel however emphasized some high-precision tool coming from practical astronomy, in particular the computation of elements, that is, the main constants (aberration, nutation, refraction) to take into account in the reduction of astronomical data. "Every new inquiry, increasing the weight of the result, issueing [sic] from the combination of this and former inquiries, the remaining error, probably will diminish continually; but this error, never vanishing entirely, it will (generally speaking) be necessary, to exhibit the result of a computation, depending upon some assumed values of certain Elements in a form open to further corrections" (Bessel 1875-1876, 3: 463). In other words, as a high-precision tool, mathematics could be used to reduce the errors, but remained dependent on a set of theoretical and observational assumptions.

Bessel went further and also explored various uses of mathematics that take us even closer to the idea of an instrument. When he set up his observatory in Königsberg, Bessel received a Dollond telescope of 4 feet of focal length and 2.7 inches of aperture (Bessel 1815, iii; Bessel 1875-1876, 19). As he wrote to Carl Friedrich Gauss on 30 December 1813, this was "one of the best instruments in existence," believing he would be able to observe with it angles with a precision of 1" to 2" (Gauss and Bessel 1975 [1880], 181). However, it was not perfect. In his letter to Gauss, Bessel tellingly described in the same breath a modest shade he had devised to protect his telescope from sun warmth and new methods in mathematical analysis he had come up with to improve the precision of his instrument by analyzing its small defects. Having undertaken the microscopic investigation of the small ellipticity and eccentricity of the pivot, Bessel explained that he used what he called an application of Gauss's least-square method, which he had come upon on another occasion and which he felt was "very elegant." In his later publication, Bessel explained: "Before giving the detailed investigation of this and other errors of the circle, I allow myself a digression about the 
solution of a class of equations frequently occurring in practical astronomy, which will find their application here." ${ }^{33}$

In my view, Bessel's "digression" represents the moment when he ceased to view mathematics as a tool, even a high-precision one mobilized to improve his Dollond refractor, and started to consider mathematics itself as an instrument. Mathematics as an instrument should also be submitted to the same inquiry as physical instruments and observers. In doing so, mathematics itself would be perfected not for its own sake, but for the sake of improving the precision of astronomical observations. Let us briefly say what Bessel's digression was about. It concerns Bessel's own approach at determining the coefficient of a finite trigonometric series representing a function, developed independently from Joseph Fourier's (Dutka 1995, 127). On July 2, 1818, Bessel read a paper at the Berlin Academy of Sciences where he extended his earlier digression to infinite trigonometric series, therefore providing a first formal treatment of what came to be called Fourier series. When a function of $U$ is expanded in the series (Bessel 1819; repr. Bessel 1875-1876, 1:18):

$$
\begin{gathered}
U=A^{\prime} \sin u+A^{\prime \prime} \sin 2 u+\cdots+A^{(i)} \sin i u+\cdots+B^{\prime} \cos u \\
+B^{\prime \prime} \cos 2 u+\cdots+B^{(i)} \cos i u+\cdots
\end{gathered}
$$

then, in general, the coefficients could be expressed as

$$
\left.\begin{array}{l}
A^{(i)}=\frac{1}{\pi} \int U \sin i u \cdot d u \\
B^{(i)}=\frac{1}{\pi} \int U \cos i u \cdot d u
\end{array}\right\}\left[\begin{array}{c}
\text { from } u=0 \\
\text { to } u=2 \pi
\end{array}\right] .
$$

Pointing out that this type of series expansion was useful in a variety of astronomical questions, he went on to describe the way these developments could be used to give an analytic solution of what he called the "Keplerian problem," that is, the computation of the true variation (or anomaly) of an elliptic orbit perturbed by another body. Bessel explained that the difference between the true and mean anomalies could be expressed as a trigonometric series of the mean anomaly, whose coefficient would be expressed as a power series of the eccentricity.

Pursuing his studies on that problem, Bessel presented a paper titled "Study of the Part of Planetary Perturbations Arising from the Motion of the Sun" at the Berlin Academy of

\footnotetext{
${ }^{33}$ Bessel (1819), ix; (1875-1876), 2: 24: "Ehe ich die nähere Untersuchung dieses und der übrigen Fehler des Kreises mittheile, erlaube ich mir eine Abschweifung über die Auflösung einer häufig in der praktischen Astronomie vorkommenden Classe von Gleichungen, die ihre Anwendung finden wird."
} 
Science on January 29, 1824. In this remarkable communication, he considered that when the motion of a planet around the sun was perturbed by another planet, this perturbation had two parts: the direct action of the perturbing planet and the indirect action of the sun whose trajectory was also perturbed. To tackle this problem, Bessel followed Laplace's method and expressed the problem in polar coordinates. Extending his earlier approach to this case, he found that results could be given as a function of two integrals he noted $I_{k}^{h}$ and $J_{k}^{h}$. Exploring further mathematical properties of these integrals, he established several of their mathematical properties, for example the recursive property:

$$
k I_{k}^{h-1}-2 h I_{k}^{h}+k I_{k}^{h+1}=0 .
$$

Typically, for an observatory scientist, Bessel also provided several pages of tables giving numerical values of the functions $I_{k}^{0}$ and $I_{k}^{1}$ for different values of $k$.

These expressions came to be called Bessel functions. Of the mathematical tools developed by astronomers in the early nineteenth century, they certainly are among the most prominent (see, e.g., Watson 1966; Hochstadt 1986, ch. 8). But if Bessel functions are a highprecision tool for mathematical physicists and engineers, I want to argue that, in the observatory culture, they had more similarities with instruments than with tools. Indeed, Bessel did not develop this analysis by tinkering with existing mathematics in order to improve the efficiency of an existing instrument but rather invented new mathematical theories to test Newton's theory of universal gravitation. Bessel indeed saw the finality of his investigations as addressing the question "whether astronomical theories are everywhere in such great agreement with the observations so as to reject all doubts regarding the truth of Newton's hypothesis." 34 Just like telescopes, mathematical analysis itself was in Bessel's hands an instrument that could be perfected in order to probe the very foundations of the Newtonian theory.

\footnotetext{
${ }^{34}$ Bessel (1824); repr. Bessel (1875-1876), 1: 86: “Ob aber die astronomischen Theorien allenthalben in so grosser Übereinstimmung mit den Beobachtungen sind, dass dadurch jeder Zweifel an der Wahrheit der Newton'schen Annahme zurückgewiesen wird, dieses ist eine Frage, welche wohl Niemand bejahen wird, deren genaue Erörterung jedoch sehr wichtig ist und die grössten Fortschritte der Wissenschaft verheisst." For a study of Bessel's cosmological understanding of Newton's law, see Merleau- Ponty (1983), 119-122.
} 


\section{Conclusion}

As Bessel himself had intuited (Ławrynowicz 1995, 219), mathematics would soon literally become an instrument for the discovery of new celestial bodies. On September 23, 1846, the planet Neptune was discovered at the place computed by Urbain Le Verrier (1811-1877), who would soon declare that "[t]he great instrument with the help of which all these [astronomical] questions will be solved will be none other than the study and computations of perturbations. ${ }^{, 35}$ Struck by this discovery, Alexander von Humboldt (1769-1859) was curious to know what great development of the human thought, what new "organ" (like the telescope, algebra, or analysis) to use his own term, had made this discovery possible and asked his friend the mathematician Carl Jacobi (1804-1851) for his opinion. ${ }^{36}$ In a "thunderous letter," Jacobi replied: "Good God!" This was not the result of any "deep thought, but [of] a nimble hand." No deep mathematical thinking was involved in Le Verrier's discovery. The only reason why mathematicians did not themselves take care of all astronomy was that this science relied on numerical results and that it was "boring to have to escort any thin idea with 10,000 logarithms."37

This exchange underscores discrepant conceptions of mathematics as a tool and as an instrument. It nicely illustrates the slippage that could ensue from too close an association with material devices. While in the hands of Le Verrier and Bessel, mathematical analysis and computation had become powerful instruments for astronomical research, others like Jacobi relegated this to mere manual work of deskilled computers. By emphasizing the boredom of computational work in the observatory (Donnelly 2014), Jacobi was degrading astronomers' status to that of menial workers, and the use of mathematics to the mere handling of a tool-a high-precision tool to be sure, but just a tool. "[I]f Leverrier has seen a new planet with the

\footnotetext{
${ }^{35}$ Excerpt from Le Verrier inaugural lecture at the Sorbonne; quoted in Revue scientifique et industrielle 28 (1847), 131.

${ }^{36}$ Humboldt to Jacobi (December 22, 1846); Humboldt and Jacobi (1987), 103.

${ }^{37}$ Jacobi to Humboldt (26 December 1846); Humboldt and Jacobi (1987), 104: "Du lieber Gott! Hier heißt es nicht, Gedanken tief, sondern Hand flink." Humboldt and Jacobi (1987), 105-106: "dieser Sachen kriegen erst durch die wirkliche numerische Ausfürung Werth, und es ist langweilich, jeder dünnen Gedanken sogleich mit 10,000 Logaritmen escortiren so müssen.” Humboldt himself called Jacobi’s a “donnerdend Brief.” Humboldt to Jacobi
} (December 26, 1846); ibid., 109. 
eye of mathematics, Jacobi added, I have myself given a new eye to mathematics." ${ }^{28}$ The mathematician found that toying with the instrument itself was more fun than using it. The design, care, and maintenance of such tools, he seemed to say, was of a higher purpose. Only this work ensured that mathematics remained applicable to astronomy and able to provide the required level of precision. A new conception of mathematics as Instrumentenkunde (Carl 1863) was emerging, according to which mathematics could and should be developed autonomously from the needs of astronomical workers, or any other user of mathematics, for that matter. As Jacobi famously wrote about Fourier, a question about numbers was worth as much as a question about the system of the world and mathematics ought solely to be pursued "for the honor of human spirit." 39

\section{Bibliography}

Anonymous. 1781. Biographical Memoirs of Mr. Sharp. Gentlemen's Magazine 51: 461-463. Aubin, David. 2009. Observatory Mathematics in the Nineteeenth Century. In Oxford

Handbook for the History of Mathematics, ed. Eleanore Robson and Jacqueline A. Steddal: 273-298. Oxford: Oxford University Press.

Aubin, David. 2013. On the Cosmopolitics of Astronomy in Nineteenth-Century Paris. In Astroculture: Figurations of Cosmology in Media and Arts, ed. Sonja Neef, Dietrich Boschung, and Henry Sussman, 61-84. Paderborn: Wilhelm Fink, Paderborn. Aubin, David. 2015. L'observatoire: régimes de spatialité et délocalisation du savoir, 17691917. In Histoire des sciences et des savoirs de la Renaissance à nos jours, ed. Dominique Pestre: 2:54-71. Paris: Le Seuil.

Aubin, David, Charlotte Bigg, and H. Otto Sibum, eds. 2010. The Heavens on Earth:

Observatories and Astronomy in Nineteenth-Century Science and Culture. Rayleigh: Duke University Press.

\footnotetext{
${ }^{38}$ Jacobi to Humboldt (December 21, 1846); Humboldt and Jacobi (1987), 100: "wenn
} Leverrier mit dem Auge der Mathematik einen neuen Planeten gesehen hat, habe ich damals der Mathematik ein neues Auge eingesetzt.” Jacobi was referring to his theory of elliptic functions (1829) which was used by Le Verrier in his work.

${ }^{39}$ Jacobi to Legendre (July 2, 1830) ; Jacobi (1881), 1:453: “le but unique de la science, c'est l'honneur de l'esprit humain, et [...] sous ce titre, une question de nombres vaut autant qu'une question de système du monde." In a complementary approach, one might also consider Bessel acting as a research-technologist in the sense put forward by Terry Shinn (2008). 
Bacon, Francis. 1676. The Novum Organum of Sir Francis Bacon, Baron of Verulam, Viscount St. Albans, Epitomiz'd, for a Clearer Understanding of His Natural History, Translated and Taken Out of the Latine by M.D. London: Thomas Lee.

Bangu, Sorin. 2012. The Applicability of Mathematics in Science: Indispensability and Ontology. Basingstoke: Palgrave Macmillan.

Barty-King, Hugh. 1986. Eyes Right: The Story of Dollond \& Aitchison Opticians, 1750 1985. London: Quiller Press.

Bell, Louis. 1922. The Telescope. New York: MacGraw-Hill.

Bennett, Jim. 2011. Early Modern Mathematical Instruments, Isis 102: 697-705.

Bessel, Friedrich Wilhelm. 1815. Beschreibung und Untersuchung der Instrumente. Astronomische Beobachtungen auf der Königlischen Universitäts-Sternwarte in Königsberg (1813-1814) 1: iii-xxiv. Repr.: Ueber das Dollond'sche Mittagsfernrohr und den Cary'schen Kreis. In Bessel (1875-1876), 2 :19-32.

Bessel, Friedrich Wilhelm. 1819. Analytische Auflösung der Kepler'schen Aufgabe. Abhandlungen der Berliner Akademie Akademie der Wissenschaften in Berlin. Mathematische Classe (1816-1817): 49-55. Repr. in Bessel (1875-1876), 1: 17-20.

Bessel, Friedrich Wilhelm. 1824. Untersuchung des Theils der planetaruschen Störungen, welcher aux der Bewegung der Sonne entsteht. Repr. in Bessel (1875-1876), 1: 84-120.

Bessel, Friedrich Wilhelm. 1848. Populäre Vorlesungen über wissenschaftliche Gegenstände, ed. H. C. Schumacher. Hamburg: Perthes-Besser \& Mauke.

Bessel, Friedrich Wilhelm. 1875-1876. Abhandlungen, 3 vols, ed. Rudolf Engelmann. Leipzig: Wilhelm Engelmann.

Biot, Jean-Baptiste. 1803. Essai sur l'histoire générale des sciences pendant la Révolution française. Paris: Duprat \& Fuchs.

Blondel, Claude-Joseph. 2003. Un enfant illustre de Beaugency: Le physicien et aéronaute Jacques Charles (1746-1823). Les Publications de l'Académie d'Orléans agriculture, sciences, belles-lettres et arts, no. 4 (December): 1-81.

Bréart, Victor. 1903. Questions extérieures: Léon XIII. Revue de Paris 4:865-894.

Canales, Jimena. 2001. The Single Eye: Reevaluating Ancien Régime Science. History of Science 39 (2001): 71-94.

Carl, Philipp. 1863. Die Principien der astronomischen Instrumentenkunde. Leipzig: Voigt \& Günther. 
Cassini, Jean-Dominique. 1793. Des principales observations faites depuis 1671 jusqu'en 1789, sur les phases de l'anneau de Saturne. Mémoires de l'Académie des sciences pour 1789 , p. 142-153.

Cassini, Jean-Dominique. 1810. Mémoires pour servir à l'histoire des sciences et à celle de l'Observatoire royal de Paris, suivis de la vie de J.-D. Cassini écrite par lui-même et des éloges de plusiers académiciens morts pendant la Révolution. Paris: Bleuet.

Chapin, Seymour L. The Vicissitudes of a Scientific Institution: A Decade of Change at the Paris Observatory. Journal for the History of Astronomy 21: 235-274.

Chapman, Allan. 1995. Dividing the Circle: The Development of Critical Angular Measurement in Astronomy, 1500-1850, 2nd ed. Chichester: John Wiley.

Chapman, Allan. 1996. Astronomical Instruments and Their Users: Tycho Braghe to William Lassel. Aldershot: Variorum.

Cotte, Louis. 1801. Vocabulaire portatif des mécaniques, ou definition, description abrégée et usage des machines, instrumens et outils employés dans les sciences, les arts et les métiers, avec l'indication des ouvrages où se trouve leur description plus détaillée. Paris: Delalain.

Croarken, Mary. 2003. Tabulating the Heavens: First Computers of the Nautical Almanac. IEEE Annals of the History of Computing 2: 48-61.

Crowe, Michael J. 1994. Modern Theories of the Universe: From Hershel to Hubble. New York: Dover.

Daumas, Maurice. 1953. Les Instruments scientifiques aux XVII et XVIII siècles. Paris: Presses universitaires de France.

Delambre, Jean-Baptiste. 1821. Histoire de l'astronomie moderne, 2 vols. Paris: Veuve Courcier.

De Morgan, Augustus. 1836. Arithmetic and Algebra. In: Library of Useful Knowledge, Mathematics. London: Baldwin and Cradock.

Diderot, Denis, and Jean Le Rond D’Alembert, eds. 1751-1765. Encyclopédie, , ou dictionnaire raisonné des sciences, des arts et des métiers, 17 vols. Paris \& Neuchâtel.

Donnelly, Kevin. 2014. On the Boredom of Science: Positional Astronomy in the Nineteenth Century. British Journal for the History of Science 47 : 479-503.

Dunkin, Edwin. 1896. Richard Dunkin [obituary notice]. Monthly Notices of the Royal Astronomical Society 56: 197-199.

Dunkin, Edwin. 1898. Notes on Some Points Connected with the Early History of the "Nautical Almanac." The Observatory 21: 49-53 and 123-127. 
Dunkin, Edwin. 1999. A Far Off Vision: A Cornishman at Greenwich Observatory, Autobiographical Notes by Edwin Dunkin, F.R.S., F.R.A.S. (1821-1898) With Notes on the Lives \& Work of his Father, Brother and Son, ed. P. D. Hingley and T. C. Daniel. Truro, Cornwall: Royal Institution of Cornwall.

Dutka, Jacques. 1995. On the Early History of Bessel's Functions. Archives for History of Exact Sciences 49: 105-134.

Frege, Gottlob. 1980. The Foundations of Arithmetic, trans. J. L. Austin. Oxford: Blackwell. Orig. publ. 1884.

Gauss, Carl Friedrich, and Friedrich Wilhelm Bessel. 1975/1880. Briefwechsel. [= Carl Friedrich Gauss, Werke. Ergänzungreihe, vol. 1] Hildeheim: Gorg Olms. Repr. From Briefwechsel zwischen Gauss und Bessel. Leipzig: Wilhelm Engelmann, 1880.

Grier, David Alan. 2005. When Computers were Human. Princeton: Princeton University Press.

Hammel, Jürgen. 1984. Friedrich Wilhem Bessel. Leipzig: Teubner.

Harrington, Mark Walrod. 1883-1884. The Tools of the Astronomer. The Sidereal Messenger 2:248-251, 261-268, and 297-305.

Henry, Joseph, Alexander Dallas Bache, and Benjamin Pierce. 1858. Defense of Dr. Gould by the Scientific Council of the Dudley Observatory, 3rd ed. Albany: the Scientific Council.

Herschel, John F. W. 1847. A Brief Notice of the Life, Researches, and Discoveries of Friedrich Wilhelm Bessel, Notices of the Royal Astronomical Society 1847 7: 200-214.

Hochstadt, Harry. 1986. The Functions of Mathematical Physics. New York: Dover.

Hoffmann, Christoph. 2007. Constant Differences: Friedrich Wilhelm Bessel, the Concept of the Observer in Early Nineteenth-Century Practical Astronomy, and the History of the Personal Equation. British Journal for the History of Science 40: 333-365.

Humboldt, Alexander von, and Carl Gustav Jacob Jacobi. 1987. Briefwechsel, ed. Herbert Pieper. Berlin: Akademie.

Jacobi, Carl Gustav Jacob. 1881-1884. Gesammelte Werke, 8 vols. Berlin : G. Reimer. King, Henry C. 1955. The History of the Telescope. London: Charles Griffin.

Kuhn, Thomas S. 1961/1997. The Function of Measurement in the Physical Sciences. Isis 52: 161-193. Repr. in T. S. Kuhn, The Essential Tension. Chicago: University of Chicago Press, 1997, 178-224.

Lawrynowicz, Kasimir. 1995. Friedrich Wilhelm Bessel 1784-1846, trans. Katja HansenMatyssek and Heinz Matyssek. Berlin: Birkhaüser. 
Lubbock, Constance A. 1933. The Herschel Chronicle. Cambridge: Cambridge University Press.

Mancosu, Paolo, ed. 2008. The Philosophy of Mathematical Practice. Oxford: Oxford University Press.

Merleau-Ponty, Jacques. 1983. Les Sciences de l'univers à l'âge du positivism: etude sur les origins de la cosmologie contemporaine. Paris: Vrin.

Olesko, Katherine. 1991. Physics as a Calling: Discipline and Practice in the Königsberg Seminar for Physics. Ithaca: Cornell University Press.

Pueyo, Guy. 1994. Les deux vocations de Louis Cotte, prêtre et météorologiste (1740-1815). Bulletin des Académie et Société lorraines des sciences 33:205-212.

Roque, Tatiana. 2015. L’originalité de Poincaré en mécanique céleste: pratique des solutions périodiques dans un réseau de textes. Revue d'Histoire des Mathématiques 21: 37-105.

S.-Devic, M. J. F. 1851. Histoire de la vie et des travaux scientifiques et littéraires de J[ean]D[ominique] Cassini IV. Clermont, Oise: Alexandre Daix.

Sarukkai, Sundar. 2005. Revisiting the "Unreasonable Effectiveness" of Mathematics. Current Science 88: 415-423.

Schaffer, Simon. 1988. Astronomers Mark Time. Science in Context 2: 115-145.

Schaffer, Simon. 2011. Easily Cracked: Scientific Instruments in States of Disrepair. Isis 102: 706-717.

Sheynin, O. B. 1973. Mathematical Treatment of Astronomical Observations (A Historical Essay). Archives for the History of Exact Sciences 11: 97-126.

Shinn, Terry. 2008. Research-Technology and Cultural Change: Instrumentation, Genericity, Transversality. Oxford : Bardwell Press.

Steiner, Mark. 1998. The Applicability of Mathematics as a Philosophical Problem. Cambridge, Mass.: Harvard University Press.

Taub, Liba. 2011. Reengaging with Instruments. Isis 102: 689-696.

Tuetet, Louis. 1912. Procès-Verbaux de la Commission temporaire des arts, 2 vols. Paris: Imprimerie nationale.

Van Helden, Albert, and Thomas L. Henkins, eds. 1994. Instruments in the History of Science. Special issue of Osiris 9.

Watson, G. N. 1966. A Treatise of the Theory of Bessel Functions, 2nd ed. Cambridge: Cambridge University Press.

Wigner, Eugene P. 1960. The Unreasonable Effectiveness of Mathematics in the Natural Sciences. Communications on Pure and Applied Mathelatics 13: 1-14. 
Wise, George. 2004. Civic Astronomy: Albany's Dudley Observatory, 1852-2002.

Astrophysics and Space Science Library, Dordrecht: Kluwer.

Wise, M. Norton, ed. 1995. The Values of Precision. Princeton: Princeton University Press.

Withold, Torsten. 2006. Lost on the Way From Frege to Carnap: How the Philosophy of Science Forgot the Applicability Problem. Grazer Philosophische Studien 73: 62-82.

Wolf, Charles. 1902. Histoire de l'Observatoire de Paris de sa foundation à 1793. Paris: Gauthier-Villars. 


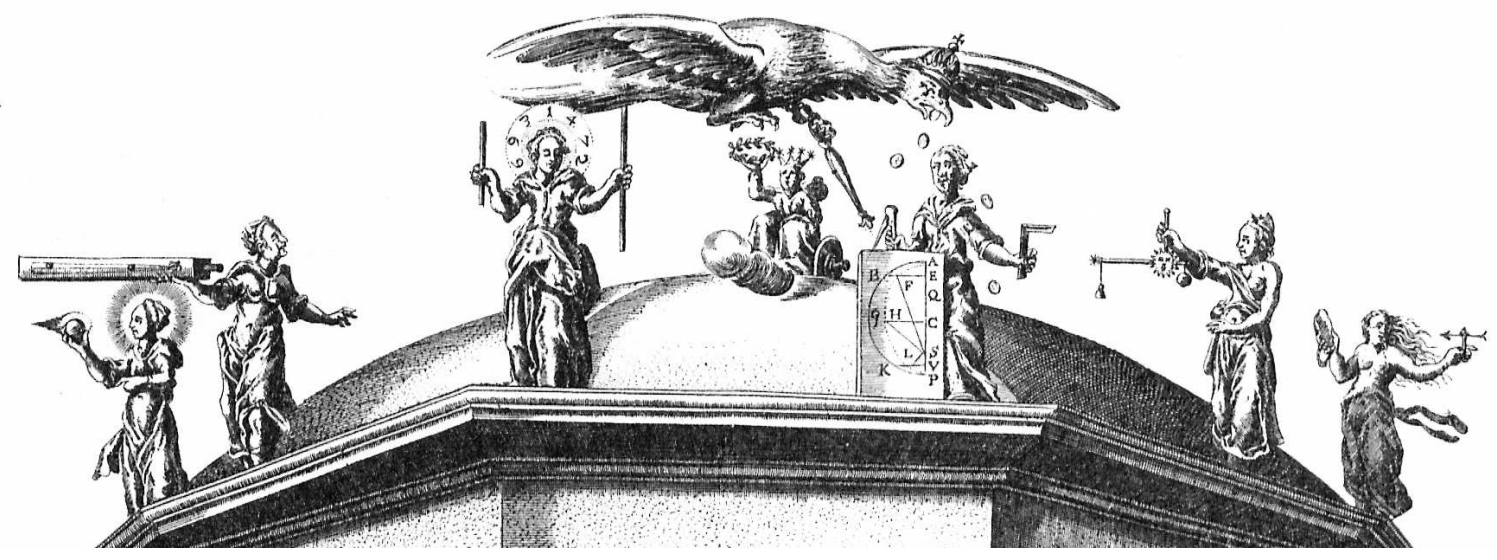

Figure 1: On the top of the allegorical kiosk pictured on the frontispiece of Johnannes Kepler's Rudolphine Tables (1627). Muses are holding some of the principal tools and instruments used by Kepler, from left to right: what looks like a representation of an eclipse; a telescope with line drawing used in optical theory inside; logarithms represented by Napier's computing rods and the number 6931492, a close approximation of $\ln 2$; geometry holding compass and set square in hand with a representation of an ellipse; an unequal-arm balance, and magnetism represented by loath stone and compass. 